\title{
An overview of a heavy rain event in southeastern Iberia: the role of large-scale meteorological conditions
}

\author{
F. Valero, M. Y. Luna, M. L. Martín \\ Dpto. Astrofísica y CC. de la Atmósfera, Facultad de CC. Físicas, Universidad Complutense de Madrid, 28040 Madrid, Spain
}

Received: 3 January 1996 / Revised: 4 November 1996 / Accepted 26 November 1996

\begin{abstract}
The heavy rain event of 30 January to 4 February 1993 in the Segura Basin in SE Iberia is investigated. The study emphasizes the atmospheric processes that led to thunderstorm development. The meteorological scenario has been separated into preconvective and convective periods and into large-scale and subsynoptic settings. The warm, moist air flow from the Mediterranean Sea, channelled by a high-over-low blocking pattern with a cold front over southeastern Iberia appears to be the main reason that helped trigger a severe weather occurrence. The study of the mesoscale environment parameters showed an enhanced conditional unstability through a deep troposphere layer with a moderate to strong vertical wind shear that promoted conditions to allow organization of long-lived convective structures.
\end{abstract}

\section{Introduction}

Heavy rain events have been studied because of their potential for producing catastrophic effects. These significant meteorological events have been analyzed not only because of the direct impact of their severe weather, but also because they provide an excellent example of complex interactions between mesoscale and synoptic scale processes which often occur prior to and during the initiation of thunderstorms. Bluestein (1982), Maddox and Doswell (1982) and Maddox (1983) have studied cases involving such interactions and speculated that processes occurring near the surface usually are critical in storm initiation. Chen and Chang (1980), Tao and Ding (1981) and Kuo et al. (1986) have analyzed the influence of large-scale circulation features over Asia and the western Pacific on the occurrence of heavy rain events in this part of the world.

Southeastern Spain is occasionally subject to this type of event where phenomena characterized by the lack of motion associated with blocking patterns exist, i.e., when systems do not progress at all within the latitude belt of the baroclinic westerlies. Such blocking situations are frequently accompanied by extreme weather. Heavy rainfall episodes are a characteristic of the late summer and autumn weather regimes for SE Spain and Balearic Islands (Font, 1983; Tout and Wheeler, 1990; Wheeler, 1991). Here however, we present an analysis of the heavy rain event which came into being in winter 1993, from 30 January to 4 February over the Segura Basin in SE Spain. This area was subjected to very heavy rain with flooding caused by repeated storms. This was a significant meteorological event not only because of the widespread property damage and numerous injuries, but also because it was an unusual winter thunderstorm whose results were notably underestimated. It cannot be denied that SE Spain is closely monitored by forecasters because of the disastrous potential of these storms, but it is also true that the mesoscale extent of the storm makes its location and severity inherently difficult to forecast.

The purpose of this study is to suggest a general scenario for those key features that are believed to have played a significant role in developing such a heavy rain event. Emphasis will be placed on those special characteristics of this unusual winter phenomenon, the consequences of which were overlooked. We will examine the synoptic conditions that led to this severe rain event and analyze both its evolution and mesoscale or subsynoptic features.

The following sections will be addressed. First, a description of the watershed as well as a revision of the most usual convective parameters to identify convective features are taken into account. Next, an analysis of the characteristics conducive to development of severe weather producing floods in southeastern Iberia is completed on the basis of large-scale and subsynoptic settings for both preconvection and convection stages. Finally, we discuss the storm event and give some conclusions in the last section. 


\section{Watershed and convective parameters}

The Segura Basin covers an area of some $15 \times 10^{3} \mathrm{~km}^{2}$ across part of southeast Iberia (Fig. 1) and a striking feature is its extreme water deficiency. This area is relatively small about $150 \mathrm{~km}$ in width and is bounded by a coastline about $100 \mathrm{~km}$ in length. The topographical features of the watershed correspond largely with the hill tops. Associated with such topographical fluctuations, are the mesoscale convergence zones and mesoscale vortices that have been documented worldwide (Parsons et al., 1990).

In this work, a large number of stations has been selected to provide a reasonably representative precipitation dataset. The network of 180 rain gauges measuring 24-h totals (see Fig. 1) since 30 January to 4 February 1993 period was used to provide rainfall distributions over the Segura Basin. The database information is supported by daily standard level charts for the surface, 500 and $300 \mathrm{hPa}$ levels.

Routine radiosonde data at Murcia station were used to describe the vertical troposphere structure. From these data, standard tools of convective storm analysis such as stability indices which are good indicators of convective activity were computed. We shall consider TTI, LI and $K I$. Miller (1972) defined the totals-totals index (TTI) as the sum of the $850 \mathrm{hPa}$ temperature and dewpoint temperature minus twice the $500 \mathrm{hPa}$ temperature. Galway (1956) defined the lifted index $(L I)$ as the temperature excess at $500 \mathrm{hPa}$ of the environment with respect to an air parcel in the moist layer lifted to its lifted condensation level, and then lifted moist-adiabatically above such a level. George (1960) defined the K index (KI) as the $850 \mathrm{hPa}$ temperature minus the $500 \mathrm{hPa}$ temperature, added to the $850 \mathrm{hPa}$ dewpoint temperature, minus the $700 \mathrm{hPa}$ dewpoint-temperature depression.

The convective available potential energy $(C A P E)$ is one of the most important parameters to capture moisture and conditional instability information. The
CAPE is essentially the "positive area" on a thermodynamic diagram, i.e., the area between the environmental temperature sounding, $T^{\prime}(z)$, and the temperature of an undiluted parcel, $T(z)$, ascending moist-adiabatically from the level of free convection $(L F C)$ to the equilibrium level $(E L)$,

$C A P E=\int_{L F C}^{E L} g \frac{T(z)-T^{\prime}(z)}{T^{\prime}(z)} \mathrm{d} z$

Zawadzki et al. (1981) found that this single thermodynamic parameter was highly correlated with maximum convective rainfall rates on both hourly and daily time scales. However, in their study there were a significant number of days that showed high values of $C A P E$, but on which there was no convective rainfall thus indicating that dynamical forcing becomes a major control on initiating and maintaining extratropical convective systems.

To quantify the relative effects of buoyant instability and vertical shear, Weisman and Klemp (1982) used a non-dimensional parameter, known as the bulk Richardson number $(B R N)$, to categorize numerically convection. The $B R N$ is defined as

$B R N=\frac{C A P E}{S^{2}}$

where $S^{2}=\frac{1}{2}\left(\bar{u}_{6}-\bar{u}_{0.5}\right)^{2}$ and $\bar{u}_{6}$ and $\bar{u}_{0.5}$ are the pressure-weighted mean vector wind speeds in the lowest 6 and $0.5 \mathrm{~km}$, respectively. $B R N$ is the ratio of $C A P E$ to a quantity proportional to the square of the mean vertical shear integrated over height as an indicator of storm type. CAPE represents the maximum possible amount of environmental potential energy that can be converted into the portion of the updraft's kinetic energy that is associated with vertical motion. $S^{2}$ represents the kinetic energy extracted from the mean flow into the updraft. Therefore, $B R N$ represents the relative balance of certain factors thought to be important in

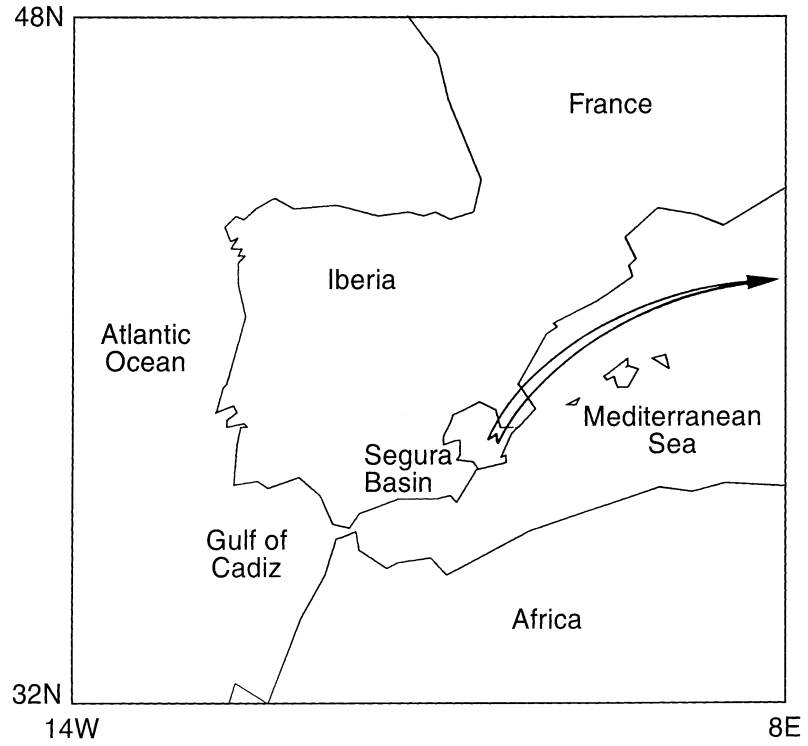

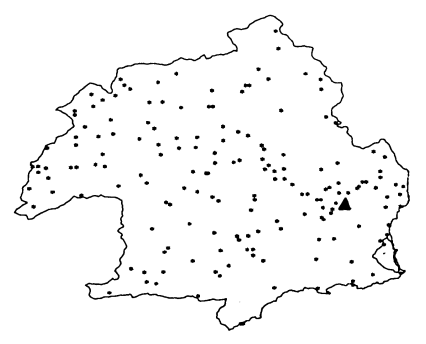

Fig. 1. Iberian Peninsula map indicating location of Segura Basin. Locations of precipitation gauges are shown by asterisks. Location of Murcia radiosonde station is shown by triangle 
controlling storm structure and evolution. However, some limitations arise in interpreting storm characteristic based on this single parameter. First, the buoyancy calculation does not include the vertical distribution of moisture in the sounding. Next, $B R N$ does not consider the important effects of directional turning of the wind shear vector which may have significant influence on storm development. Because different severe storm types may exist in the same $B R N$ regimes, $B R N$ cannot distinguish clearly (Droegemeier et al., 1993) between environment supporting storm types and others with some similarity and so more emphasis will be given to the $C A P E$ and $S^{2}$ than to $B R N$ itself in this study.

The convective inhibition $(C I N)$ is the work needed to lift an air parcel from rest at the surface to the $L F C$. It is the negative of the area enclosed by the environmental temperature profile and the dry and moist adiabats connecting the surface to the $L F C$ on a thermodynamic diagram. The $C I N$ is, by its very nature, a measure of the strength of the "cap" when a stable layer or capping inversion is present.

\section{The heavy rain event of winter 1993}

A number of atmospheric processes which may have been involved in the formation of this event are presented for consideration in this section. The episode has been separated into the preconvective and convective periods and each one of them into two general space-scale categories: synoptic and subsynoptic scale processes.

\subsection{Preconvection, large-scale setting}

The large-scale conditions can establish an environment thermodynamically and dynamically prepared for the development of midlatitude convective systems which may produce widespread heavy rain. In some instances, such as a prefrontal squall line formation, existence of stagnant low-pressure systems and combination of upper- and low-level jets, the synoptic scale environment not only establishes the setting favourable for the convection genesis, but it can also supply the trigger to develop and organize the convective systems.

In the period leading up to the storms, a high pressure system over Europe and a low pressure system over the Gulf of Cádiz with a slow-moving cold front extending over south Iberia and North Africa are shown up on the surface chart, as revealed in Fig. 2a. The location of this low encourages southeasterly airflow along most of Spain's eastern coast. This flow, from Africa towards Iberia, consists of dry, hot air and is able to obtain vast amounts of water vapour when entering and crossing the Mediterranean Sea. There is reason to believe that such a cold front constituted a critical control for intense convection to be triggered. There was low-level forcing for ascent along such a slow-moving cold front, with a moist southeasterly flow off the Mediterranean Sea. Additionally, new growth was topographically forced by a range of hills just inland which may well favour mesoscale convergence as documented by Parsons et al. (1990).

Conditions aloft (Fig. 2b) show a worthless zonal index of the upper westerlies over Iberia. The upperlevel flow is a cold cut-off circulation centred over Gulf of Cádiz which had carried cold Polar Air over the western Mediterranean Sea. Meanwhile, a ridge lies over central Europe. Throughout the preconvection stage, the low becomes associated with a jet stream across North Africa where an amplifying baroclinic wave is noted as displayed in Fig. 2b. The jet stream interacts with the trough and there is warm advection and cold advection downstream and upstream from the trough, respectively. In this stage, the jet streak is in phase with the trough. Uccellini and Johnson (1979) proposed a dynamic mechanism by which, in the exit region of the jet streak, the surface-induced ageostrophic flow would
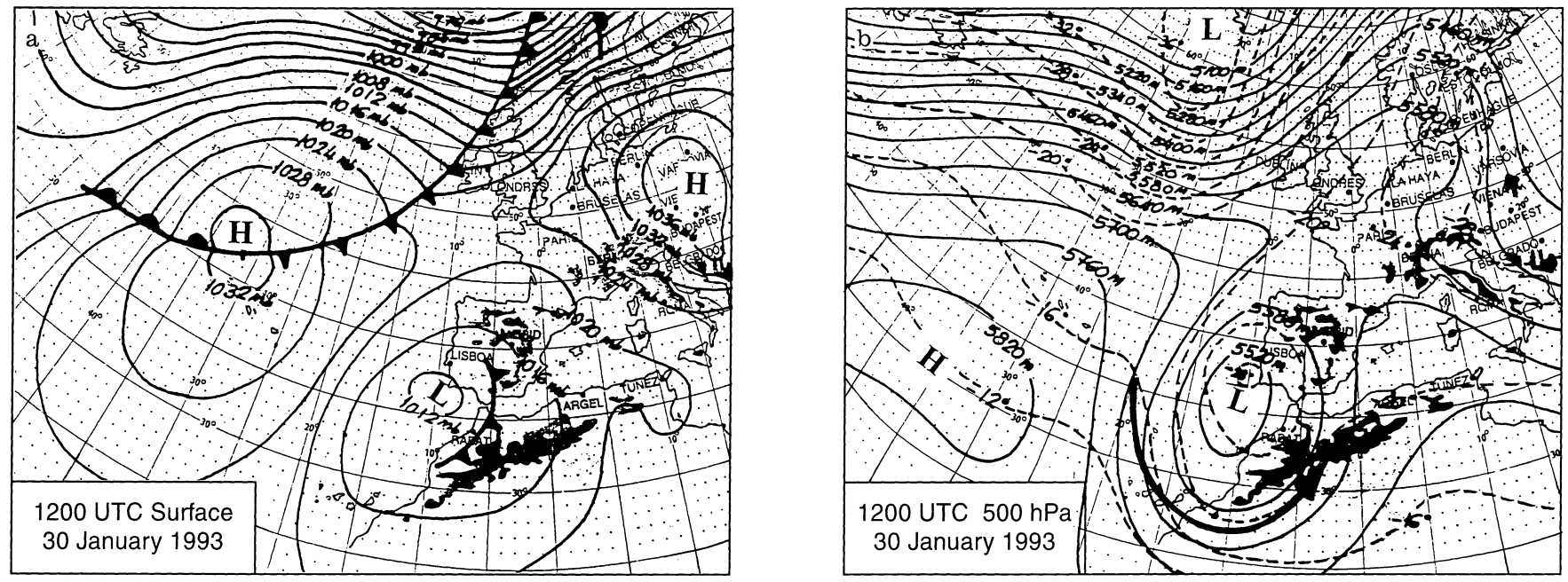

Fig. 2a, b. Synoptic situation at 1200 UTC on 30 January 1993. a Surface analysis (pressure contours every $4 \mathrm{hPa}$ ); b $500 \mathrm{hPa}$ analysis (height contours, every $60 \mathrm{~m}$, are shown by continuous lines; temperature contours, every $4{ }^{\circ} \mathrm{C}$, are indicated by dashed lines) 
be directed toward the pole, while the ageostrophic flow aloft would be toward the equator. Cold air on the poleward side, and warm air on the equatorward side lead to establishing of some lower-level warm advection and cold advection aloft and so upward motions on the left side of the exit region set in to destabilize the atmosphere on this side. All these features merge to drive large-scale instability conditions needed to initiate convective motions over the southwestern Mediterranean area and, therefore, over SE Spain.

The total amount of rainfall at the Segura Basin watershed and the evolution of local pressure are depicted in Fig. 3. It is noteworthy that a simultaneous increase in local surface pressure in the pre-storm stage is associated with a small amount of rainfall measured within such an area.

Large-scale processes are likely to change the local environment over the studied area. Differential temperature advection contributes to a local steepening of the lapse rate. Doswell et al. (1985) have argued that when regional areas of unstable air in the midtroposphere are advected and/or dynamically produced over low-level moist air, a deep convectively unstable environment is created. In the case of storms forming over much of western Mediterranean Basin, the origin of the unstable air rests sometimes on the juxtaposition of upper cold, dry air and lower warm, moist air advection. Large-scale conditions in such a case may well play some role in the initiation as well as in modifying the local thermodynamics environment.
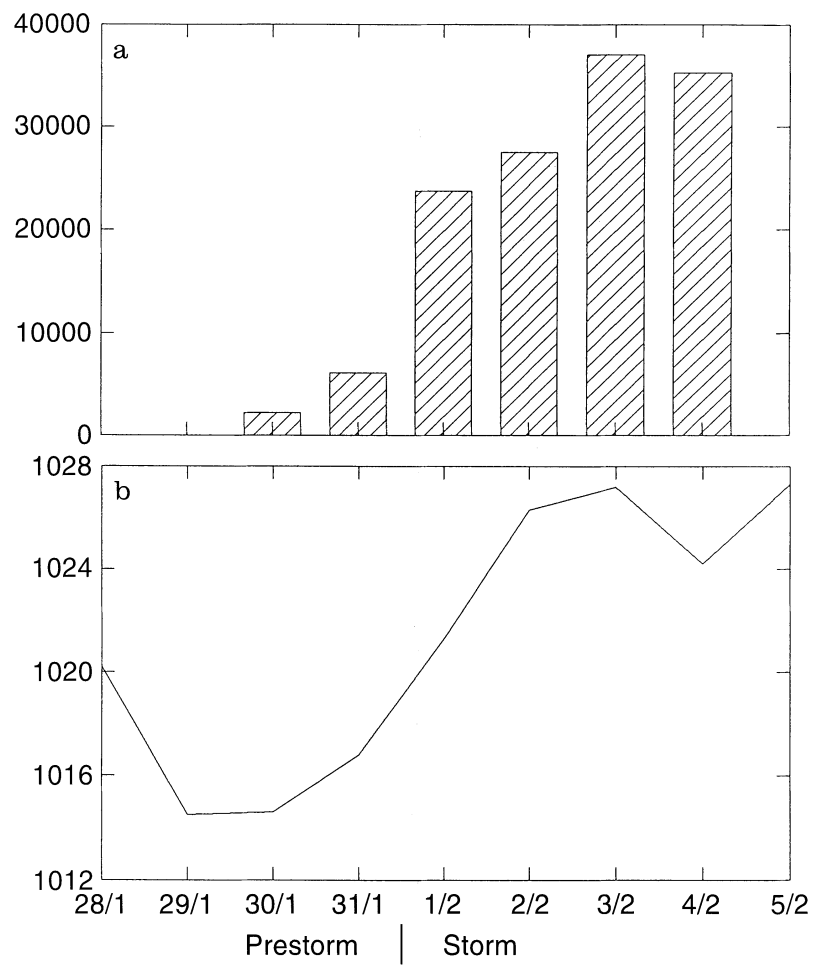

Fig. 3a, b. Time series during the prestorm and storm regimes of a daily precipitation totals ( $\mathrm{mm})$ over whole Segura Basin and $\mathbf{b}$ air pressure $(\mathrm{hPa})$ at Murcia station

\subsection{Preconvection, subsynoptic setting}

Surface observations had reported high-based (above $2500 \mathrm{~m}$ ) cloudiness on 29 January at Murcia station. For this date, the 1200 UTC Murcia sounding in Fig. 4 shows a surface-based inversion. The dewpoint line emphasizes the dryness of the 1000-400 $\mathrm{hPa}$ layer. These features and the values of both $T T I$ and $L I$ stability indices do not indicate that thunderstorms were likely to develop. In fact, a value of 27 for $T T I$ and 14 for $L I$ indicate little likelihood of thunderstorms. That sounding is produced when dry low-level air lies beneath moist, maritime air. Convection that occurs in such an environment is usually high-based. Precipitation falls out through the deep, dry subcloud layer and evaporates, cooling the air and creating vigorous downdrafts that can later produce strong surface winds. If we set the initial preconvective sounding (Fig. 4) against the final preconvective sounding (Fig. 5) on 31 January, we can see how some increase in conditional instability is noted associated with differential temperature and moisture advection. Furthermore, Fig. 5 shows up a shallow surface-based, nearly adiabatic layer characterized by easterly flows carrying warm and moist air off the Mediterranean Sea. This layer is separated from a dry, cold layer above by a relatively stable layer. A large TTI of 49 , a $L I$ of zero and a $K I$ of 17 associated with this sounding were indicatives of potential for convective storms.

In the preconvective period some cumulus clouds with sufficient vertical development to produce light showers were noted. On 30 and 31 January scattered

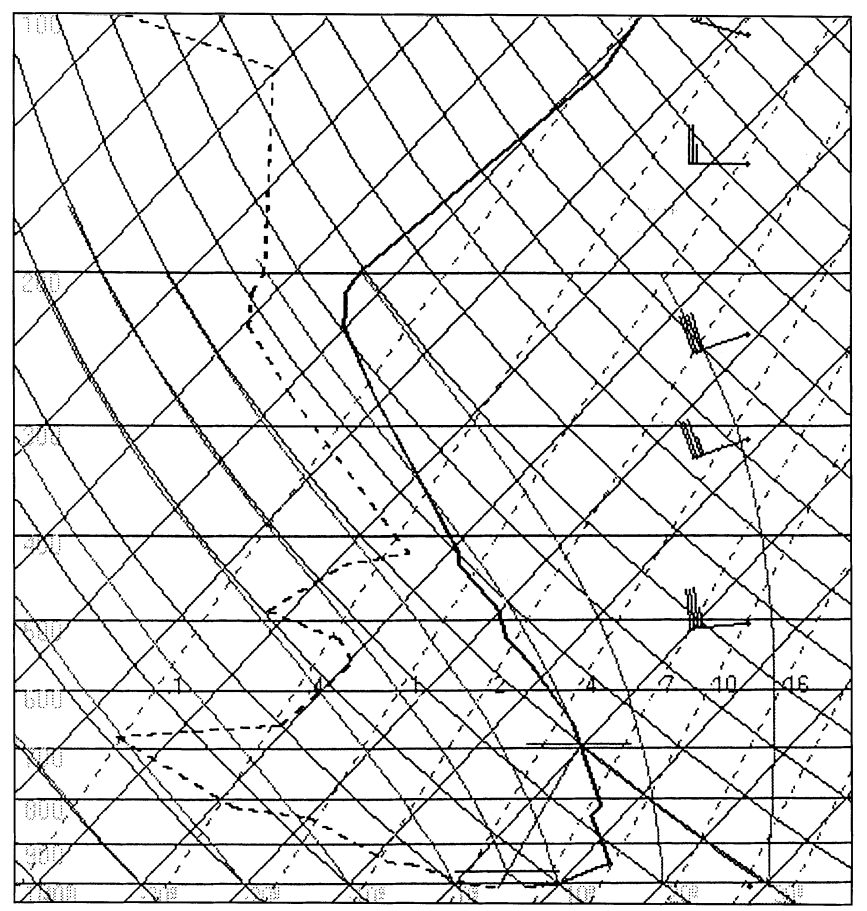

Fig. 4. Skew $T$ - $\log p$ plot of Murcia sounding for 1200 UTC on 29 January 1993. Solid line is the temperature plot $\left({ }^{\circ} \mathrm{C}\right)$; dashed line is the dewpoint plot $\left({ }^{\circ} \mathrm{C}\right)$; wind barbs are in knots 


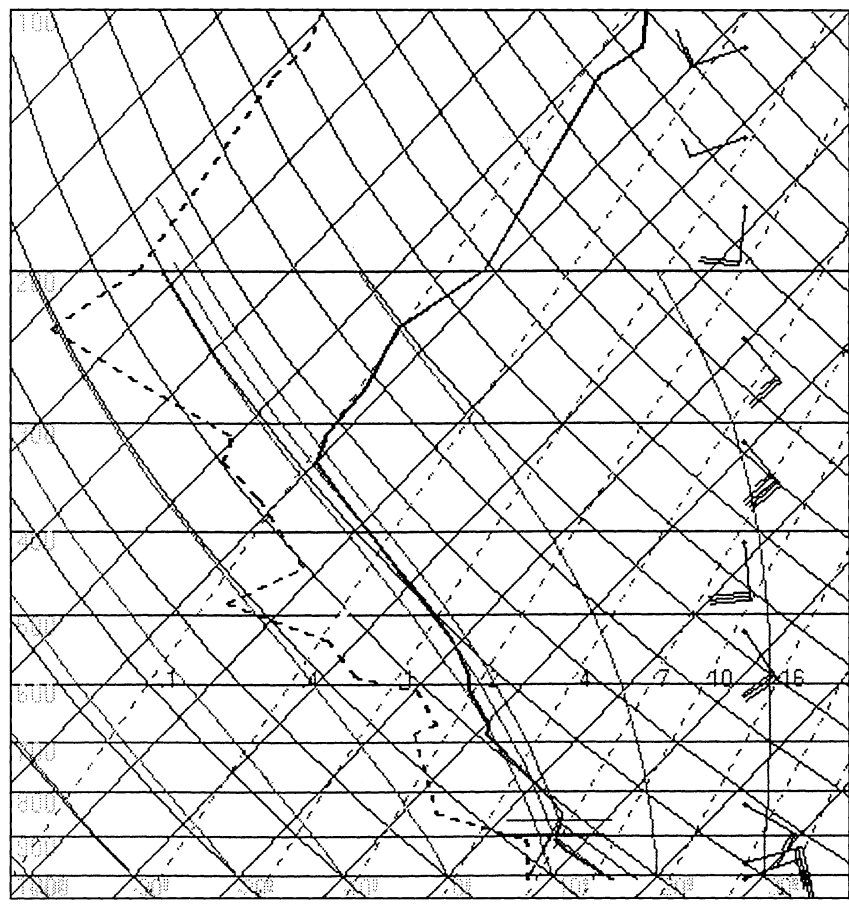

Fig. 5. Same as Fig. 4. but for 31 January 1993 at 1200 UTC

outbreaks of rainfall, up to $20 \mathrm{~mm} \mathrm{day}^{-1}$, were recorded over most of the watershed (Fig. 6a, b). Furthermore, the wind shear is non-unidirectional as displayed in the right part of Fig. 5. A most superficial look at this figure reveals that the wind shear vector veers with height. As presented in Klemp and Wilhelmson (1978), the development of a severe right-moving storm is favored creating updraft intensification in such a frame.

Figure 7 displays the three-day back-trajectories on 1000,850 and $500 \mathrm{hPa}$ pressure levels at Murcia up to 31 January. It should be noted that the source of air in the middle and upper troposphere is the North Atlantic which arrives on Segura Basin after going the long way round North Africa. In contrast, in the lower troposphere, at the $1000 \mathrm{hPa}$ level, moist air masses come from the inner Mediterranean Sea. The short-run but warm airmass associated with the $850 \mathrm{hPa}$ back-trajectory is usually sufficient for the boundary layer to be laden with moisture as well and to allow for the increased amount of potential instability to be ensured over the Segura Basin.

\subsection{Convection, large-scale setting}

In this case study, the cut-off over North Africa and the transition of the ridge to close the high pressure system over Central Europe was a large-scale benchmark for the development into a extreme storm event. This pattern is referred to as 'split flow' by Sumner (1954), because of the fact that the basic current split around the northern ridge-southern low system. An argument in support of that approach is that this large-scale pattern promotes and reinforces the low-level moist, warm advection encouraged by the meridional low. In fact, as the upper-level dipole sets in and bears a strong resemblance to that of Fig. 8, the high-over-low blocking pattern enhances and persists over a number of days, thereby ensuring a regular warm, moist air supply to eastern Iberia.

The IR satellite image in Fig. 9 for 1 February provides some evidence of the cloud pattern over southeastern Iberia which is, at first sight, very suggestive of a cloud band growing in depth. At this time, the low-level southeasterly wind is blowing from North Africa across a belt of sea. The image shows that the clouds are organized in a band-like pattern along the direction of the wind flow which can be recognized from the general orientation of the brighter NW-to-SE bands. Blown along by strong wind in the upper troposphere, the cloud pattern is seen as extensive and persistent feature in the IR image. Downwind at Segura Basin the contrast between the warm surface and the colder cloud tops becomes more evident as the clouds grow in depth and the cloud-top temperatures decrease. The IR image on the next day (Fig. 10) shows brighter bands of clouds lying along the low-level wind flow with darker, warmer (thinner clouds) areas outside.

One of the most striking features of this situation it is the fact that the watershed precipitation amount increases (Fig. 3a) within a high pressure setting (Fig. 3b). In our case study, it is possible a meteorological setting where seemingly opposite events are not entirely and mutually exclusive. The increase in pressure is forced by the reinforcing of the blocking-pattern high. However, the low-level moisture advection is reinforced as well, thereby enhancing environment potential instability, apart from the microphysics processes such as evaporative cooling, latent-heat releases and orographic influences.

At the end of the storm period, on 5 February, both the moist low-level advection and the $500 \mathrm{hPa}$-height dipole had been removed as seen in Fig. 11. The situation over the Iberian peninsula, corresponds indeed with a rather featureless surface pressure chart and a weak, cyclonic upper-level circulation. At that time and over the following days, the rainfall amounts were no longer significant and no well-organized patterns developed.

\subsection{Convection, subsynoptic setting}

On 1 February, the 1200 UTC sounding (Fig. 12) is representative of the "tropical sounding" (McCaul, 1987). A deep moist layer, up to about $9 \mathrm{~km}$ above ground level, without a stable layer can be observed. The lapse rate is less than dry adiabatic but greater than moist adiabatic, i.e., the sounding is conditionally unstable. The TTI, $L I$ and $K I$ values of $57,-2$ and 29, respectively suggest an increase of convection probability over the Segura Basin. Without a capping inversion, but with a deep moist layer, there is then the possibility of widespread convection. In fact, daily precipitation became organized west of the Segura Basin with a maximum of up to $50 \mathrm{~mm}$ or so to the northwest as seen in Fig. 6c. 

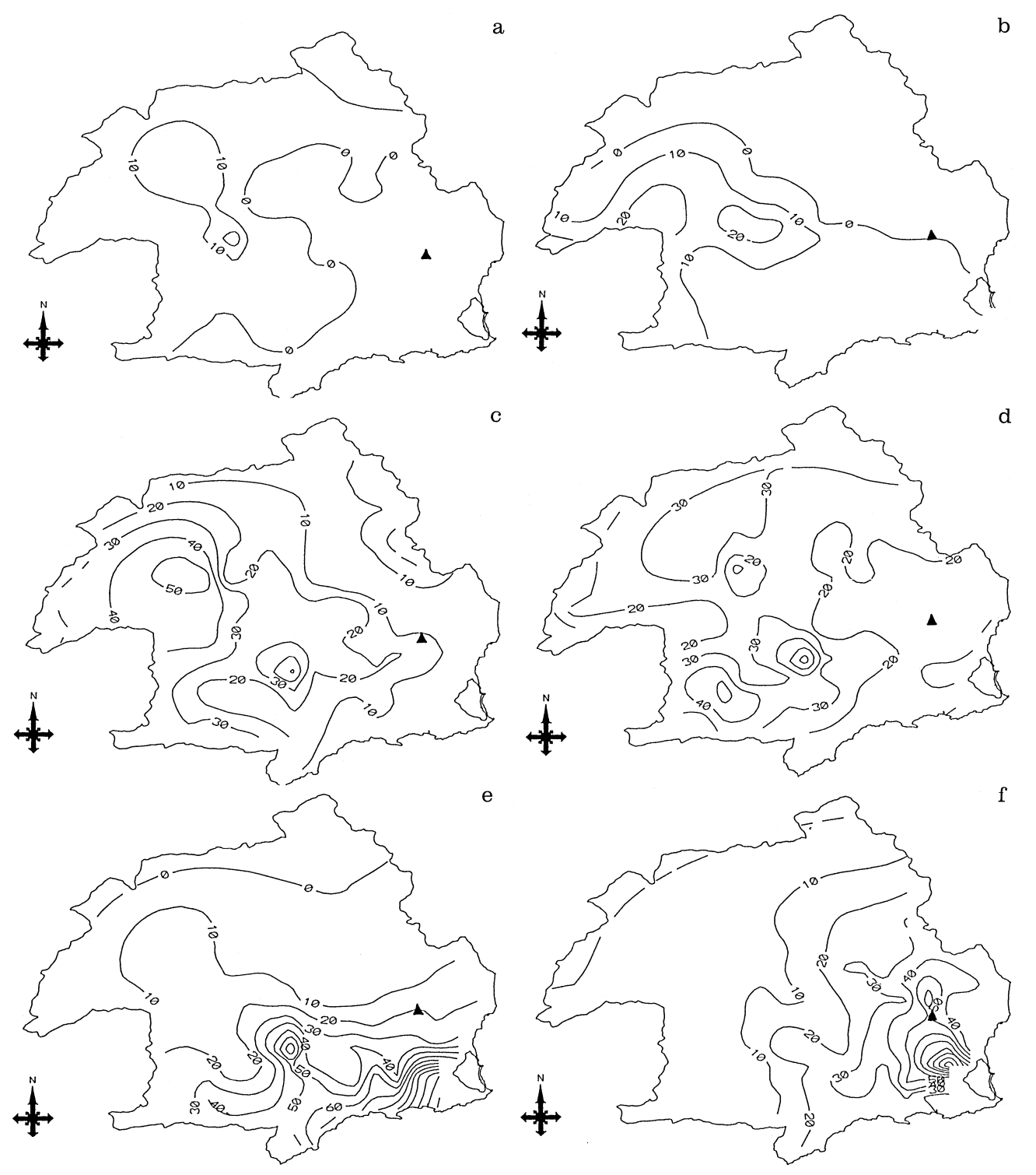

Fig. 6a-f. Isohyets of daily rainfall $(\mathrm{mm})$ over Segura Basin for a 30 January; b 31 January; c 1 February; d 2 February; e 3 February and f 4 February 1993 The study domain was mapped at a scale of 1:850000. Location of Murcia station is shown by triangle

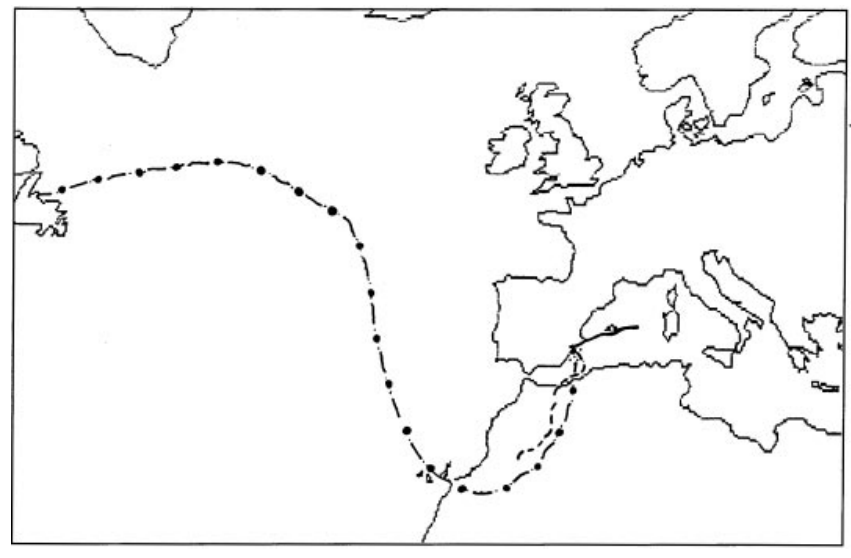

Fig. 7. Three-day back-trajectories on $1000 \mathrm{hPa}$ (solid line), $850 \mathrm{hPa}$ (dashed line) and $500 \mathrm{hPa}$ (dashed-dotted line) pressure levels at Murcia station up to 31 January 1993

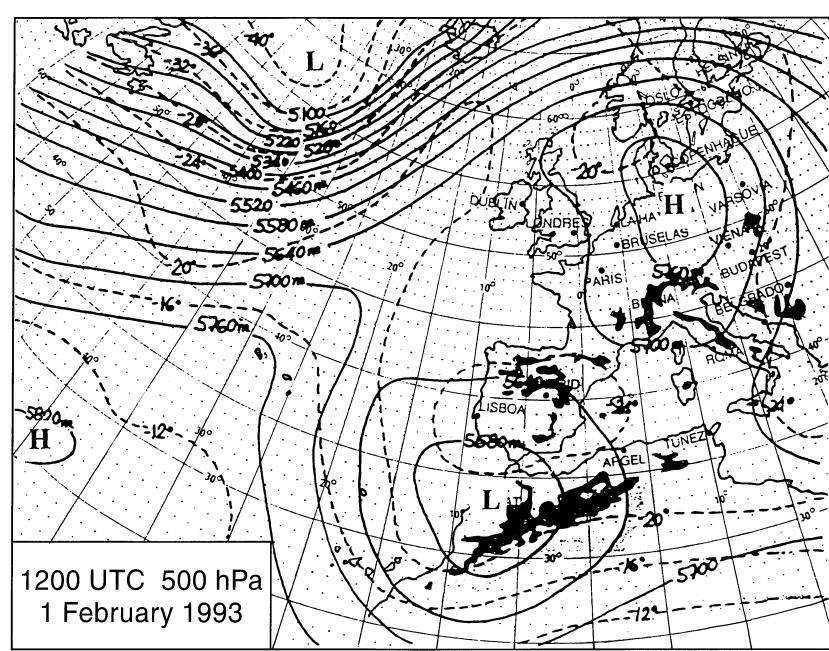

Fig. 8. The $500 \mathrm{hPa}$ analysis for 1 February 1993 at 1200 UTC. Height contours, are every $60 \mathrm{~m}$, (continuous lines) and temperature contours are every $4{ }^{\circ} \mathrm{C}$, (dashed lines) 


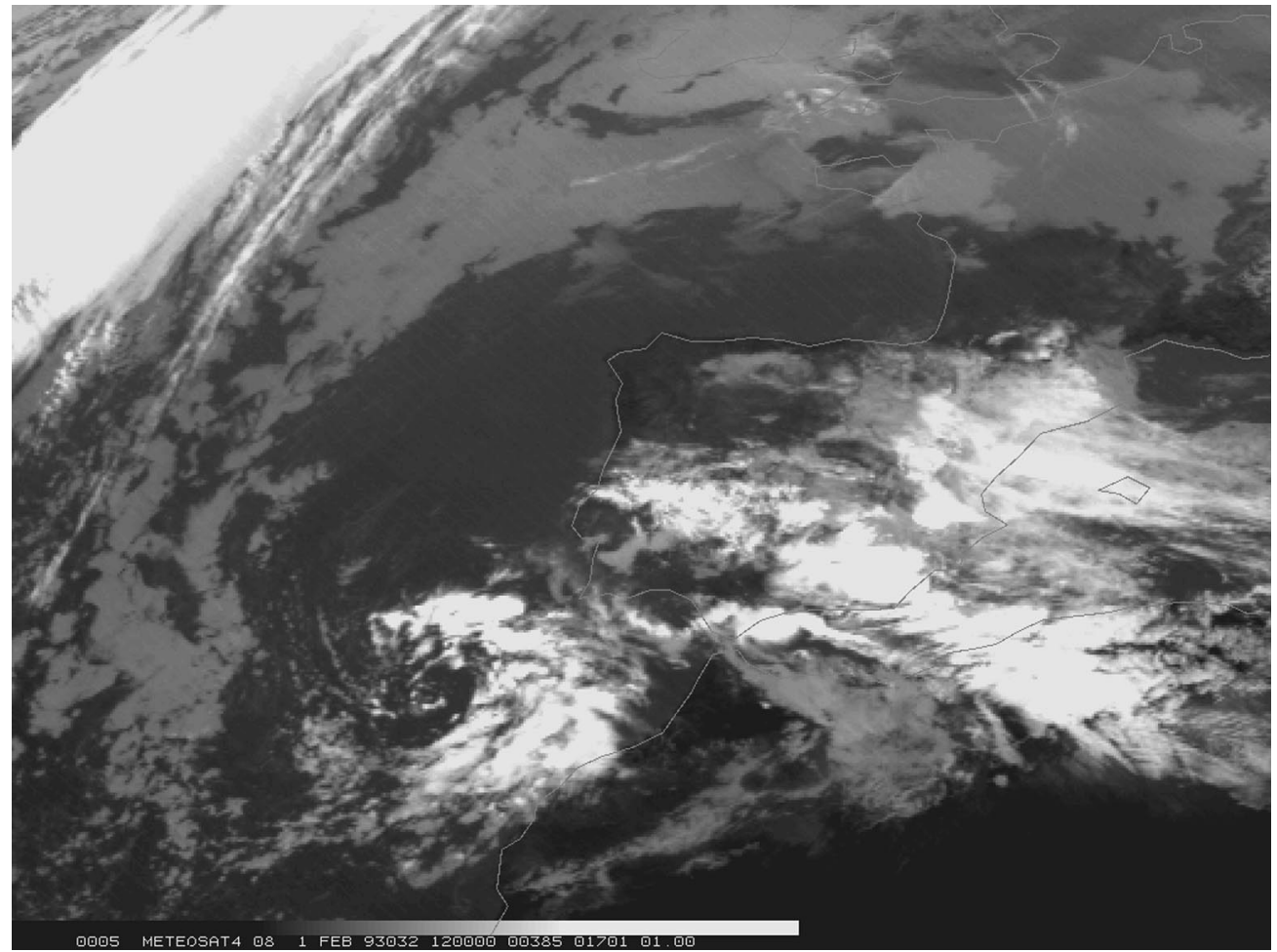

Fig. 9. Meteosat infrared image for 1 February 1993 at 1200 UTC
$B R N$ s became much the same as those for the prestorm period. Substantial negative buoyancy $(C I N)$ must often be overcome before a rising parcel reaches its $L F C$. High values of $C I N$ are conducive to lower-level channelling of the easterly warm, moist flow towards Segura Basin. In our case, we noticed in Fig. 13 that $C I N$ values decreased from $1331 \mathrm{~J} \mathrm{~kg}^{-1}$ on 29 January (preconvective period) to nearly zero on 1 February within convective period. Simultaneously, some rather weaker increases in $C A P E$ were observed. As a result, a strong lifting had been needed to initiate deep convection.

In addition to large-scale parameters such as jet streak- and/or cold front- induced upward motion and low-level moisture advection which are important in both tropical and extratropical systems, vertical wind shear became a critical control over the maintenance of deep, precipitating convection. Computed vertical wind shear values between 10 and $20 \mathrm{~m} \mathrm{~s}^{-1}$ occurred in this case throughout the storm period. Yet, wind shear did

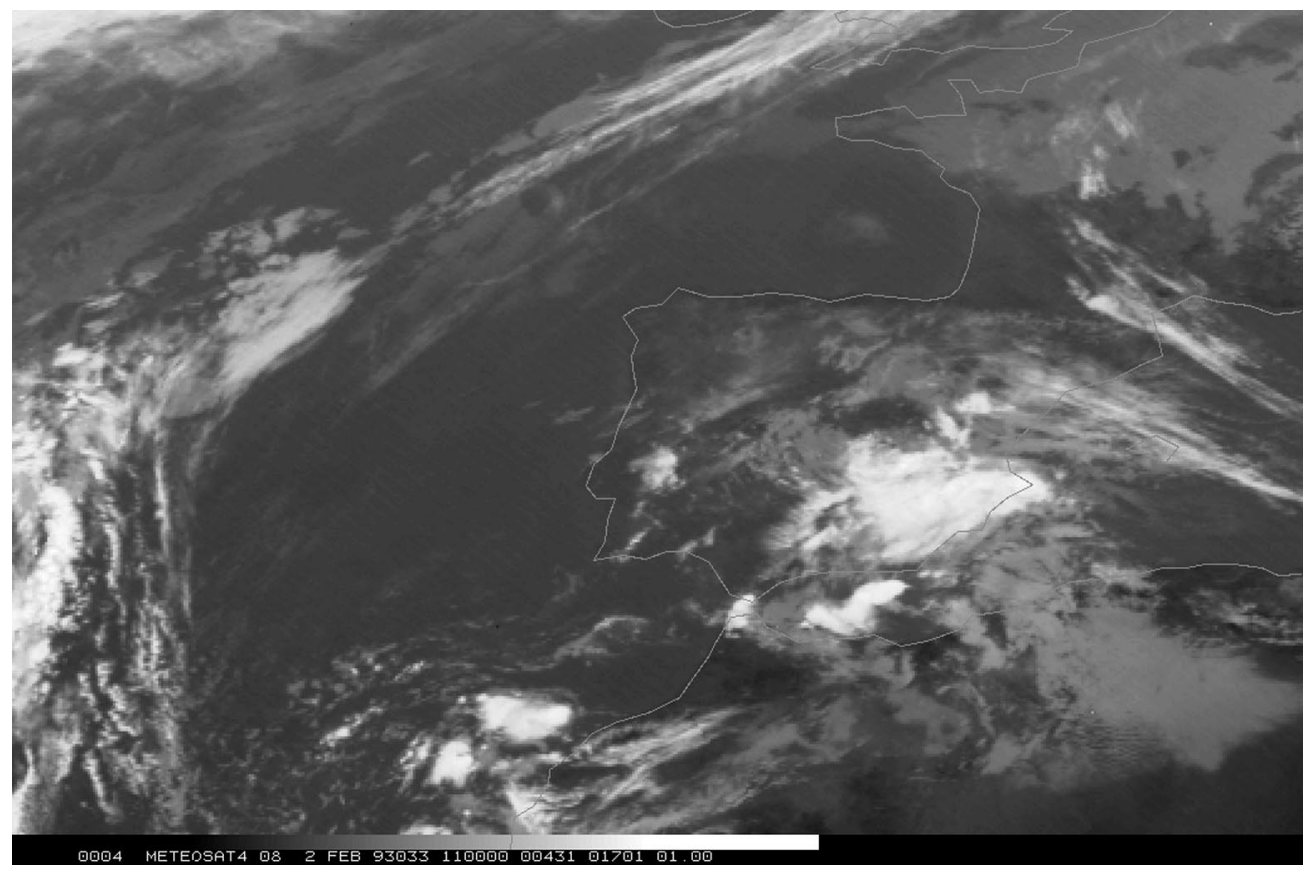

Fig. 10. Same as Fig. 9 except for 2 February 1993 at 1100 UTC 


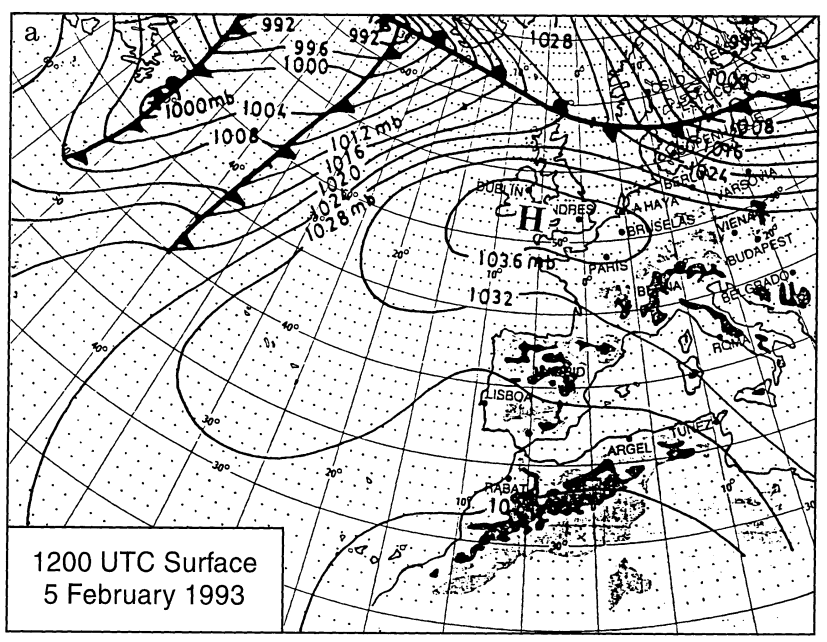

Fig. 11a,b. Same as Fig. 2 except for 5 February 1993 at 1200 UTC

have a enough strength to promote necessary conditions to organize a long-lived convective structure.

Local atmosphere conditions during the later part of the event were analogous to those previously described on 1 February. Widespread convective activity throughout the Segura Basin continued until 4 February also resulting in heavy rains spreading out over much of the Segura Basin's area (Fig. 6d-f). Here, the maximum precipitation shifted eastward approaching the coastline with exceptional amounts of rainfall about $150 \mathrm{~mm}$ day $^{-1}$ or so.

\section{Summary}

In the latter part of January and early February 1993 excessive rainfall in SE Spain triggered widespread

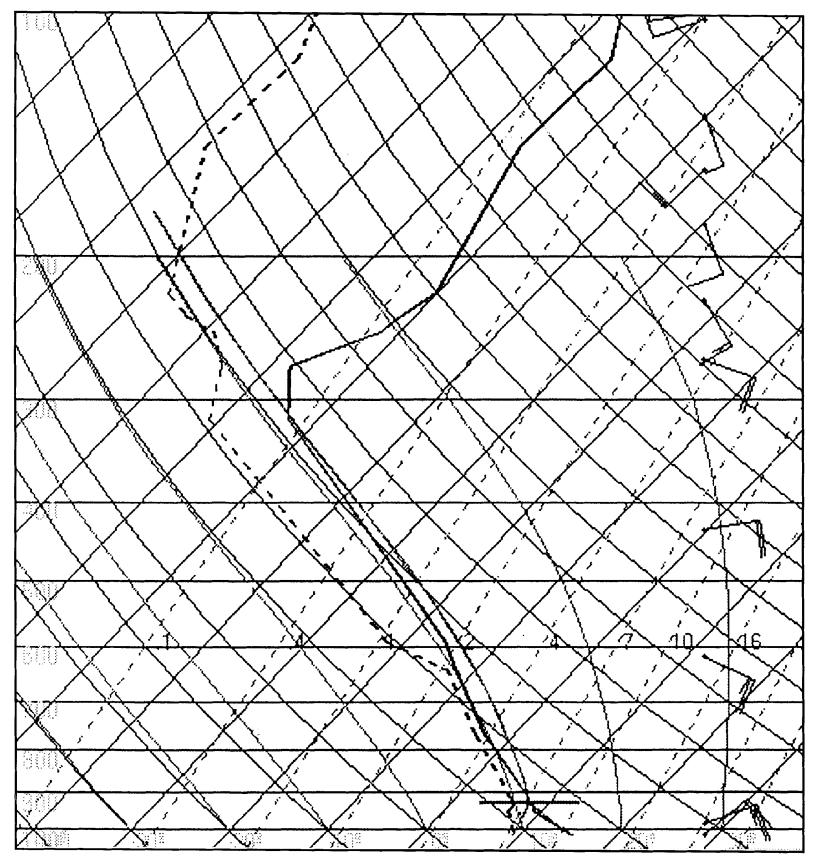

Fig. 12. Same as Fig. 4. except for 1 February 1993 at 1200 UTC

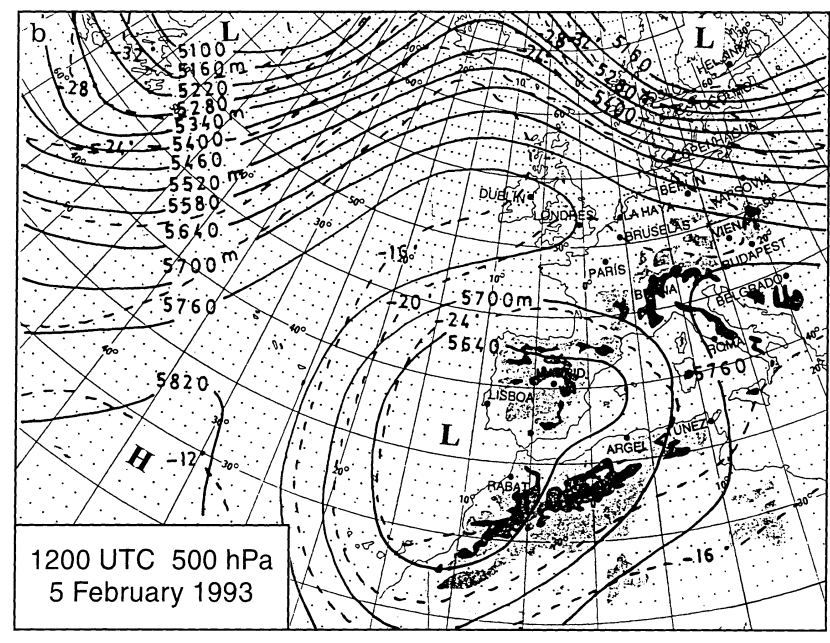

flooding. This study has focused on a meteorological analysis of this event by analyzing its synoptic and subsynoptic features to illustrate a conceptual framework for understanding the processes leading to intense convection at this area. Such events are a typical autumn time phenomenon over SE Spain. However, this case was a significant weather event not only because the hazard that it caused, but also because it was an unusual winter storm which was inherently more difficult to forecast and therefore underestimated by forecasters.

The explosive storm development over a fairly small area of Spain was due to a number of factors all coming together at the same place and time. The contribution from large-scale conditions was crucial. If the warm, moist air had not been forced to rise there would have been no initial release of conditional instability over SE Iberia (itself enhanced by channelling of the flow from

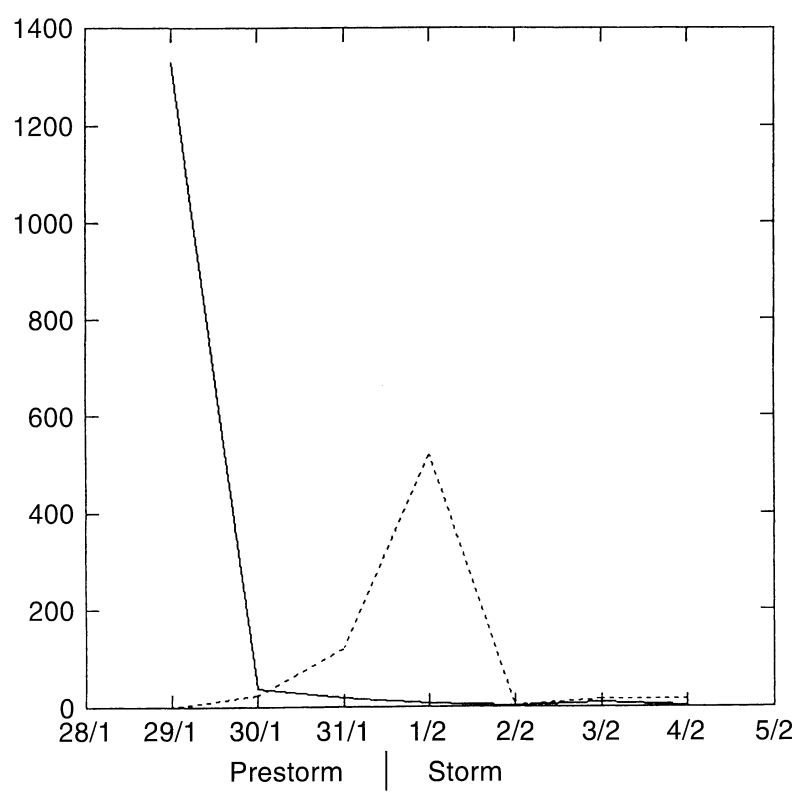

Fig. 13. Time series of CAPE (dashed line) and CIN (solid line) values during the prestorm and storm regimes. Both parameters are in $\mathrm{J} \mathrm{kg}^{-1}$ 
the Mediterranean Sea). A large-scale critical control, in our opinion, was the cut-off over North Africa and the transition of the ridge over Central Europe to a closed high. The channelling effect meant that there was continuing destabilization of the atmosphere. The upper trough acted, together with the proximity of a cold front to southeastern Iberia, to induce mass ascent and therefore, release of conditional instability and subsequently severe weather.

Any rapid changes in surface pressure whether falls or rises, signal rapid development. It is necessary to understand what is causing the large pressure changes (a rise in our case-study) before a forecast can be made. To help making forecasts in similar situations a number of indications have been reached from this case-study, which may allow warnings of severe weather. These situations include:

1. Strong low-level advection of warm, moist air forced by a high-over-low blocking pattern over western Europe.

2. A low-level forcing for ascent such as a slow-moving front and/or topographical features undertaken to channel moist flow off the Mediterranean Sea.

3. A conditionally unstable layer through a deep troposphere layer as well as moderate to strong vertical wind shear of the horizontal wind able to persist during the storm period.

Acknowledgements. The authors would like to thank the Spanish Meteorological Institute for providing the data. This work was supported in part by the Ministerio de Educación y Ciencia under Grant FPI. We are also very much indebted to the referees for their helpful discussions concerning this work.

Topical Editor L. Eymard thanks F. Roux and another referee for their help in evaluating this paper.

\section{References}

Bluestein, H. B., A wintertime mesoscale cold front in the southern Plains, Bull. Am. Meteorol. Soc., 63, 178-185, 1982.

Chen, G. T.-J, and C.-P. Chang, The structure and vorticity budget of an early summer monsoon trough (Mei-Yu) over southeastern China and Japan, Mon. Weather Rev., 108, 942-953, 1980.

Doswell, C. A., F. Caracena, and M. Magnano, Temporal evolution of $700-500 \mathrm{hPa}$ lapse rate as a forecasting tool, Preprints 14th Conf. Severe local storms, Indianapolis, Am. Meteorol. Soc., 398-401, 1985.
Droegemeier, K. K., and S. M. Lazarus, The influence of helicity on numerically simulated convective storms, Mon. Weather Rev., 121, 2005-2029, 1993.

Font, I., Climatología de España y Portugal, Instituto Nacional de Meteorología, Madrid, 1983.

Galway, J. G., The lifted index as a predictor of latent instability, Bull. Am. Meteorol. Soc., 37, 528-529, 1956.

George, J. J., Weather forecasting for aeronautics, Academic Press, 1960.

Klemp J. B., and R. B. Wilhelmson, Simulations of right- and leftmoving storms produced through storm splitting, J. Atmos. Sci., 35, 1097-1110, 1978.

Kuo, Y.-H., L. Cheng, and R. A. Anthes, Mesoscale analyses of the Sichuan flood catastrophe, 11-15 July 1981, Mon. Weather Rev., 114, 1984-2003, 1986.

McCaul, E. W. Jr, Observations of the hurricane "Danny" tornado outbreak of 16 August 1985, Mon. Weather Rev., 115, 12061223, 1987.

Maddox, R. A., and C. A. Doswell III, An examination of jet stream configuration, $500 \mathrm{mb}$ vorticity advection and low-level thermal advection patterns during extended periods of intense convection, Mon. Weather Rev., 110, 184-197, 1982.

Maddox, R. A., Large-scale meteorological conditions associated with midlatitude, mesoscale convective complexes. Mon. Weather Rev., 111, 1475-1493, 1983.

Miller, R. C., Notes on analysis and severe-storm forecasting procedures of the Air Force Global Weather Central, Air Weather Service Tech. Rep. 200, Air Weather Service, Scott Air Force Base, 1972.

Parsons, D. B., B. F. Smull, and D. K. Lilly, Mesoscale organization and processes: Panel report, in (Ed.) D. Atlas, Radar in meteorology (Boston, Mass. American Meteorological Society), 461472, 1990.

Sumner, E. J., A study of blocking in the Atlantic-European sector of the northern hemisphere, Q. J. R. Meteorol. Soc., 80, 402416, 1954.

Tao, S.-Y., and Y.-H. Ding, Observational evidence of the influence of the Quinghai-Xizang (Tibet) Plateau on the occurrence of heavy rain and severe convective storms in China, Bull. Am. Meteorol. Soc., 62, 23-30, 1981.

Tout, D., and D. A. Wheeler, The early autumn storms of 1989 in eastern Spain, J. Meteorol., 15, 238-248, 1990.

Uccellini, L. W., and D. R. Johnson, The coupling of upper and lower tropospheric jet streaks and implications for the development of severe convective storms. Mon. Weather Rev., 107, 682-703, 1979.

Wheeler, D. A., Majorca's severe storms of september 1989: a reminder of Mediterranean uncertainty, Weather, 46, 21-26, 1991.

Weisman, M. L., and J. B. Klemp, The dependence of numerically simulated convective storms on vertiical wind shear and buoyancy, Mon. Weather Rev., 110, 504-520, 1982.

Zawadzki, I., E. Torlaschi, and R. Sauvageau, The relationship betwenn mesoscale thermodynamic variables and convective precipitation. J. Atmos. Sci., 38, 1535-1540, 1981. 